\title{
HPMC Polymers and Xanthan Gum Assisted Development and Characterization of Stavudine Extended Release Floating Tablets
}

\author{
Purushottam Shridhar Gangane ${ }^{1, *}$, Tejas Pachpute ${ }^{2}$, Debarshi Kar Mahapatra ${ }^{3}$, \\ Nilesh Manoharrao Mahajan ${ }^{1}$ \\ ${ }^{1}$ Department of Pharmaceutics, Dadasaheb Balpande College of Pharmacy, Nagpur, Maharashtra, INDIA. \\ ${ }^{2}$ Department of Industrial Pharmacy, I.B.S.S. College of Pharmacy, Malkapur, Buldhana, Maharashtra, INDIA. \\ ${ }^{3}$ Department of Pharmaceutical Chemistry, Dadasaheb Balpande College of Pharmacy, Nagpur, Maharashtra, INDIA.
}

\begin{abstract}
Objectives: Stavudine has a low half-life of 0.8-1.5 hr and therefore needs recurrent administration to sustain stable beneficial drug plasma levels. In order to enhance and preserve the stable drug level of stavudine for round the clock, gastroretentive systems (floating low-density formulations that cause buoyancy on the gastric fluid in the stomach) may prove to be advantageous for releasing the drug content from the matrix tablet reservoirs for several hours. Materials and Methods: The current research endeavors towards formulating the stavudine floating tablet formulations (F1-F9) employing rate modifying polymers such as HPMC K15M, xanthan gum and HPMC K100M using multiple punch tablet compression machine containing $9 \mathrm{~mm}$ diameter, round flat-faced punches to form $80 \mathrm{mg}$ tablet with a batch size of 100 . The drug-polymer compatibility was investigated through Fourier-Transformed Infrared Spectroscopy (FTIR) and Differential Scanning Calorimetry (DSC). Results: The stavudine floating tablet formulations were successfully fabricated. The pre-compression characteristics (tapped density, bulk density, Hausner's ratio, Carr's index and angle of repose) as well as postcompression characteristics (appearance, hardness, dimension, drug content, friability, swelling index, weight variation, in vitro drug release, in vitro buoyancy, accelerated stability and drug release kinetics for 90 days) of the formulations were comprehensively studied. Conclusion: This research study on stavudine will definitely open several new milestones for anti-retroviral pharmacotherapeutics in the upcoming future perspectives by enhancing the half-life of the drug employing the floating extended-release attributes.
\end{abstract}

Keywords: Stavudine, Floating, Tablet, Gastroretentive, Xanthan, HPMC.

\section{INTRODUCTION}

The United States Food and Administration (USFDA) approved anti-retroviral drug stavudine, is a nucleoside thymidine analog that is employed exclusively for treating HIV-AIDS and its related conditions. ${ }^{1}$ It is recommended often as a single product or with additional antiviral drugs for various ailments. ${ }^{2}$ Under the influence of the cellular kinases, the drug molecule is metabolized into stavudine triphosphate (the active metabolite). ${ }^{3}$ This metabolite, in turn, inhibits the HIV-1 reverse transcriptase by contending with the thymidine triphosphate and ultimately leading to the termination of deoxyribonucleic acid (DNA) chain, followed by its integration into the viral DNA. ${ }^{4}$ Stavudine is characteristically administered through the oral route as a capsule formulation and an oral solution. ${ }^{5}$ It has been perceived that the AIDS patients receiving stavudine in therapeutic dose develop neuropathy and lactic acidosis. ${ }^{6}$ The side effects of stavudine are usually dose-dependent and thus reducing the total administered drug level will eventually reduce the associated toxicity.
Submission Date: 08-01-2021; Revision Date: 20-06-2021; Accepted Date: 09-08-2021

DOI: 10.5530/ijper.55.3s.175 Correspondence: Dr. Purushottam S. Gangane, Associate Professor, Department of Pharmaceutics, Dadasaheb Balpande College of Pharmacy, Nagpur-440037, Maharashtra, INDIA. Phone: +91 9420338543, Email-p.gangane@gmail. com

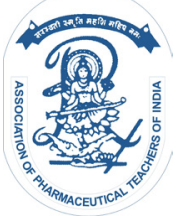

www.ijper.org 
Stavudine has a low half-life of $0.8-1.5 \mathrm{hr}$ and consequently necessitates recurrent administration to sustain stable beneficial drug plasma levels. ${ }^{8}$

In order to enhance and maintain the steady drug level of stavudine for round the clock, gastroretentive systems (floating low-density formulations that cause buoyancy on the gastric fluid in the stomach) may prove to be beneficial for releasing stavudine from the matrix tablet reservoirs for several hours. ${ }^{9}$ This will lead to an expansion in the drug solubility in acidic enhancement, extend the gastric residence time, the drastic enhancement in the patient compliance, results in the drug bioavailability enhancement, diminution in the wastage of drug, extensive advantages for patients, minimizes the dose-related side effects and new curative possibilities. ${ }^{10}$ Drawing inspiration from the studies done so far and employing the above logics for providing long-term anti-retroviral pharmacotherapeutics, the formulation of extended-release floating stavudine tablets remain a bright option. ${ }^{11}$

The current research endeavors towards the development of stavudine floating tablet formulations (F1-F9) employing rate modifying polymers such as HPMC K15M, xanthan gum and HPMC K100M using multiple punch tablet compression machine containing $9 \mathrm{~mm}$ diameter, round flat-faced punches to form $80 \mathrm{mg}$ tablet with a batch size of 100 . The rationality of using these three specific polymer excipients such as HPMC $\mathrm{K} 15 \mathrm{M}$, xanthan gum and HPMC K100M is that these semi-synthetic to natural components played key role in fabricating a traditional floating tablet product, a number of previously reported floating formulation has HPMC as the primary excipient; secondly, the existing combination is novel for producing the floating formulation of this particular drug material; and thirdly, these polymers have good characteristics for both wet granulation process as well as dry granulation process. The drug-polymer compatibility was investigated through Fourier Transformed Infrared Spectroscopy (FTIR) and Differential Scanning Calorimetry (DSC). The pre-compression characteristics (tapped density, bulk density, Hausner's ratio, Carr's index and angle of repose) and post-compression characteristics (appearance, hardness, dimension, drug content, friability, swelling index, weight variation, in vitro drug release, in vitro buoyancy, accelerated stability and drug release kinetics for 90 days) of the fabricated formulations were comprehensively studied.

\section{MATERIALS AND METHODS}

\section{Materials}

Stavudine was obtained from Cipla Ltd., Mumbai, India as a gift sample. The polymers (HPMC K15M and HPMC K100M) and microcrystalline cellulose $\mathrm{PH}$ 102 were purchased from Griffon Laboratories Pvt. Ltd., Mumbai, India. Analytical grade hydrochloric acid $(\mathrm{HCl})$ and ethanol (95\%) were purchased from SD Fine-Chem Ltd., Mumbai, India. Qualigens Fine Chemicals Ltd., Mumbai, India supplied the xanthan gum, sodium bicarbonate, polyvinylpyrrolidone, magnesium stearate, methanol, propylene glycol, isopropyl alcohol, acetone, sodium chloride and talc.

\section{Instruments}

Electronic balance (Shimadzu ${ }^{\circledR}$ BL-220H), Bulk density apparatus (Indolab ${ }^{\circledR}$ VTAP/MATIC-II), Hot air oven (Chemi ${ }^{\circledR}$ Equipments), Friability apparatus (Veego ${ }^{\circledR}$ Scientific VFT-DV), Hardness tester (Monsanto ${ }^{\circledR}$ ), UVVis spectrophotometer (Shimadzu ${ }^{\circledR} 1700$ Pharmaspec), FTIR spectrophotometer (Shimadzu ${ }^{\circledR}$ S4008), Differential scanning calorimeter (Shimadzu ${ }^{\circledR}$ DSC 60), USP tablet dissolution apparatus Type-II (Veego ${ }^{\circledR}$ Scientific VDA-8DR), Vernier caliper (Indolab ${ }^{\circledR}$ ), Stability chamber $\left(\right.$ Labtech $\left.^{\circledR}\right)$, Standard sieve (Jayant ${ }^{\circledR}$ Scientific Ltd., India) and Sixteen punch tablet compression machine $\left(\mathrm{Cadmach}^{\circledR}\right)$ were utilized exclusively for developing, optimizing and characterizing the stavudine floating tablet formulations.

\section{Drug-polymer compatibility}

\section{Fourier Transformed Infrared Spectroscopy}

For formulating the floating formulation, the compatibility of the antiviral drug stavudine with the applied polymers (HPMC K15M, xanthan gum and HPMC $\mathrm{K} 100 \mathrm{M}$ ) was studied through the physical mixture by utilizing the FT-IR spectrometer ( $\mathrm{KBr}$ disk method) in the scanning range of 4000 to $500 \mathrm{~cm}^{-1}{ }^{12}$

\section{Differential Scanning Calorimetry}

The compatibility of the pure drug stavudine with the used hydrophilic polymers was investigated from the physical mixtures by employing the differential scanning calorimeter where the sample for analysis were heated under the inert nitrogen atmosphere $(20 \mathrm{~mL} / \mathrm{min})$ in the $30-300^{\circ} \mathrm{C}$ temperature range at $10^{\circ} \mathrm{C} / \mathrm{min}$ heating rate. ${ }^{13}$

\section{Formulation of powder blend}

The ingredients employed in the formulation of the blend (Table 1) were carefully weighed and separately 


\begin{tabular}{|c|c|c|c|c|c|c|c|c|c|}
\hline Ingredients & F1 & F2 & F3 & F4 & F5 & F6 & F7 & F8 & F9 \\
\hline Stavudine & 100 & 100 & 100 & 100 & 100 & 100 & 100 & 100 & 100 \\
\hline HPMC K15M & 40 & 80 & 120 & - & - & - & - & - & - \\
\hline HPMC K100M & - & - & - & 40 & 80 & 120 & - & - & - \\
\hline Xanthan gum & - & - & - & - & - & - & 40 & 80 & 120 \\
\hline Sodium bicarbonate & 90 & 90 & 90 & 90 & 90 & 90 & 90 & 90 & 90 \\
\hline Polyvinylpyrolidone & 50 & 50 & 50 & 50 & 50 & 50 & 50 & 50 & 50 \\
\hline Microcrystallne Cellulose pH 102 & 206 & 166 & 126 & 206 & 166 & 126 & 206 & 166 & 126 \\
\hline Talc & 9 & 9 & 9 & 9 & 9 & 9 & 9 & 9 & 9 \\
\hline Magnesium Stearate & 5 & 5 & 5 & 5 & 5 & 5 & 5 & 5 & 5 \\
\hline Total & 500 & 500 & 500 & 500 & 500 & 500 & 500 & 500 & 500 \\
\hline
\end{tabular}

passed through \#40 mesh. The drug content was taken in a mortar and blended suitably with the limited quantity of polymers using a pestle. Further, the residual mass of the polymer added and the content was blended for the duration of $20 \mathrm{~min}$. The blend was passed through the \#20 mesh and further evaluated for the flow attributes.

\section{Characterization of powder blend}

\section{Bulk density}

It applies to particle packing. To calculate the amount of medication filling the volume in $\mathrm{g} / \mathrm{mL}$, bulk density was used. Using a graduated cylinder, the bulk density of the ingredients was measured. It is the ratio of the gross powder mass to the amount of powder in bulk. By pouring the weighted sum of powder into a graduated measurement cylinder, it was weighed and the volume was noted. It is expressed in $\mathrm{g} / \mathrm{mL}$ and measured using the formula below: ${ }^{14}$

$$
\text { Bulk density }=\frac{\text { Mass of the powder }(\mathrm{W})}{\text { Untapped volume }(\mathrm{VO}) \mathrm{g} / \mathrm{ml}}
$$

\section{Tapped density}

It is the ratio of the total mass of powder to the amount of powder being tapped. The tapped amount was determined according to USP by tapping the 10, 500 and 1250 powder taps in the tap density apparatus. The mix was subjected to 500 taps; the percent variation in volume was measured and subjected to a further 1250 taps and the percent variation from the formula was calculated: ${ }^{14}$

Tapped density $(\rho t)=\frac{\text { Mass of the powder }(w)}{\text { Tapped volume of the powder }(V f)}$

\section{Hausner's ratio}

It determines the flow properties of the granules and is determined from the tapped density: the ratio of bulk density. From the formula, it is decided: ${ }^{14}$

$$
\text { Hausner's ratio }=\frac{\text { Tapped density }}{\text { Bulk density }}
$$

\section{Carr's index}

A significant metric that can be derived from the bulk and tapped densities is the compressibility index. Theoretically, the thinner the compressible object, the more flowable it is. The free-flowing material is described as a material with values below 20 percent. The relationship between percent compressibility indexes and flowability is given by: ${ }^{14}$

$$
\text { Compressibility index }=\frac{\begin{array}{l}
\text { Tapped density }- \\
\text { Bulk density }
\end{array}}{\text { Tapped density }} \times 100
$$

\section{Angle of repose}

The resting angle is an example of the friction forces that occur between the components of the granule. That is the maximum possible angle between the face of the pile and the horizontal smooth surface of the granules. By passing the set volume of powder from the funnel at constant height until the top of the pile created by the powder reaches the funnel, the angle of repose was determined. By measuring the angle of repose by the process of fixed height, the flowability of the granules was determined: ${ }^{14}$

$$
\theta=\tan ^{-1}(\mathrm{~h} / \mathrm{r})
$$


where, $\theta=$ angle of repose; $h=$ height of pile; $r=$ average radius of powder cone.

\section{Compression of blend into tablets}

Using several punch tablet compression machines with $9 \mathrm{~mm}$ diameter, round flat-faced punches, the floating tablet formulations were prepared by direct compression process after the assessment of the powder blend. Each tablet had $80 \mathrm{mg}$ of stavudine, with a batch size of 100 tablets made.

\section{Evaluation of floating tablets}

\section{Appearance}

For development defects such as capping, chipping and lamination, the produced stavudine floating tablets were visually observed. All such detected defects have been identified.

\section{Dimension}

In terms of uniformity of the tablet scale, the thickness and diameter of the established stavudine floating tablets is a crucial feature and were estimated using a Vernier calliper. Three tablets were used from each of the types of tablet formulations produced and the mean values were recorded. ${ }^{15}$

\section{Hardness}

The hardness of 6 tablets was calculated using the Monsanto hardness tester from each of the Stavudine floating tablet formulations produced. Every tablet was held in between the two jaws of the Monsanto hardness tester along its oblong axis where the reading should be $0 \mathrm{~kg} / \mathrm{cm} 2$. The constant force was also applied by rotating the tester's knob until the tablet formulations were split and the value was expressed in $\mathrm{kg} / \mathrm{cm}^{2} .^{16}$

\section{Friability}

The measure of tablet power is friability. This test subjects tablets to the combined shock scrape stress by making use of a circular plastic compartment that spins at $25 \mathrm{rpm}$ speed and with each revolution further lowers the items to 6 inches distance. In the Roche Friabilator, 6 pre-weighed tablets were placed and the machine was worked for 100 revolutions. The tablets were de-dusted and measured again. Under the criteria for pharmacopoeia, a reduction of $<1$ percent in total weight is usually considered acceptable. From the following formulation, the percent friability (percent $\mathrm{F}$ ) was determined: ${ }^{17}$

$$
\% \mathrm{~F}=\frac{\text { Initial weight }- \text { Final weight }}{\text { Initial weight }} \times 100
$$

\section{Weight Variation}

20 tablets from each floating mixture were independently weighted using the balance to assess the weight difference. In order to measure the deviation, the average weight of the tablets was measured and each actual weight of the tablet was compared. The findings were analyzed from the pharmacopoeia spectrum. ${ }^{18}$

\section{Drug content}

In each batch of floating formulations, the stavudine content was determined by simply crushing the 5 tablets and taking a powder equal to $25 \mathrm{mg}$. The contents of the $100 \mathrm{~mL}$ beaker containing $0.1 \mathrm{~N} \mathrm{HCl}$ were added and mixed for $10 \mathrm{~min}$. The solution was filtered through a $0.45 \mu \mathrm{m}$ membrane filter, diluted correctly and spectrophotometrically measured the absorbance at $\lambda_{\max } 266 \mathrm{~nm}$, using blank $1 \mathrm{~N} \mathrm{HCl} .^{19}$

\section{In vitro buoyancy}

The in vitro buoyancy was determined from floating lag time and overall floating time where the floating tablets were put in a $0.1 \mathrm{~N} \mathrm{HCl}$-containing $100 \mathrm{~mL}$ beaker $\left(37^{\circ} \mathrm{C} \pm 1^{\circ} \mathrm{C}\right)$. The period taken to lift the tablet to the medium's surface is referred to as floating lag time or lag time for buoyancy. The period during which the tablets have stayed continuously on the surface of the medium, on the other hand, is referred to as overall floating time or total buoyancy time. ${ }^{20}$

\section{Swelling Index}

By assessing the weight gain, the swelling activity of the floating tablets was determined. The tablets were put at a temperature of $37^{\circ} \mathrm{C} \pm 0.5^{\circ} \mathrm{C}$ in a dissolution test apparatus basket containing $750 \mathrm{~mL}$ of $0.1 \mathrm{~N} \mathrm{HCl}$. The tablets were extracted from the dissolution medium every $1 \mathrm{hr}$. The weight was calculated on the analytical balance after draining the free water present on the surface of tablets with a tissue paper by basic blotting and the water content gained was estimated. The index of swelling (SI) was determined using a formula: ${ }^{21}$

$$
\mathrm{SI}=\frac{\text { weight of tablet at time } \mathrm{t}-}{\text { weight of tablet before immersion }}
$$




\section{In vitro dissolution studies}

The in vitro dissolution properties of the floating tablet were tested in $900 \mathrm{~mL}$ simulated gastric fluid media without any enzymes, held at a temperature of $37^{\circ} \mathrm{C} \pm 0.5^{\circ} \mathrm{C}$ at a stirring speed of $50 \mathrm{rpm}$, using the paddle-type dissolution test apparatus. The tablet was placed in the dissolution medium at the bottom of the paddle attached to a variable velocity generator. $5 \mathrm{~mL}$ of sample was extracted from each vessel at a given interval of time, pumped through a $0.45 \mu \mathrm{m}$ membrane, analytically diluted and spectrophotometrically analyzed at $\lambda_{\max } 266 \mathrm{~nm}$. The equivolume pre-warmed fresh dissolution medium was replenished with the device for each sampling to maintain the steady volume during the experiment. The total releases were carried out in a triplicate fashion from the formulations and the analysis was expressed as a percentage. ${ }^{22}$

\section{Release kinetics}

A selection of kinetic models were used to map the combined drug release data collected from in vitro drug release studies, ${ }^{23}$ where:

Zero-order is represented as the rate of the cumulative amount of drug released (Equation 1)

$$
\mathrm{C}=\mathrm{K}_{0} \mathrm{t}
$$

Where $\mathrm{K}_{0}$ is the zero-order rate constant expressed in units of concentration/time and $t$ is the time in minutes. A graph of concentration vs. time would yield a straight line with a slope equal to $\mathrm{K}_{0}$ and intercept the origin of the axes.

First-order is presented as the rate of Log cumulative $\%$ of remaining drug (Equation 2)

$$
\log \mathrm{C}=\log \mathrm{C}_{0}-\mathrm{K}_{\mathrm{t}} / 2.303
$$

Where $\mathrm{C}_{0}$ is the initial concentration of the drug, $\mathrm{K}$ is the first order constant and $t$ is the time.

Higuchi's model is depicted as the squared rate of cumulative $\%$ of drug released (Equation 3)

$$
\mathrm{Q}_{\mathrm{t}}=\mathrm{K}_{\mathrm{t}}^{1 / 2}
$$

Where $Q_{t}$ is the amount of drug release in time $t, K$ is the kinetic constant and $t$ is the time in minutes.

Korsmeyer-Peppas exponential model is Log rate of Log cumulative percentage of drug released (Equation 4).

$$
\mathrm{Mt}=\mathrm{M} 1 \frac{1}{4} \mathrm{Kt}^{\mathrm{n}}
$$

The release exponent $\mathrm{n}$ and $\mathrm{K}$ value were calculated through the slope of the straight line. If the exponent $n=0.43$ then the drug release mechanisms Fickian diffusion, if $0.43<\mathrm{n}<0.85$ then it is non-Fickian or anomalous diffusion, if $n<0.85$ mechanism is nonFickian case-II diffusion.

\section{Accelerated stability study}

Although keeping with the Q1A Recommendation of the International Council for Harmonization of Technical Specifications for Pharmaceuticals for Human Use (ICH), an accelerated stability analysis was carried out over a span of 3 months for the optimized stavudine floating tablet formulation under changed short-term conditions $\left(40^{\circ} \mathrm{C}\right.$ temperature / 75 percent relative humidity). As per the protocol, the tablet formulation was wrapped in an aluminum foil and held in the stabilization chamber. The tablets were retested for post-compression parameters after 90 days (hardness, drug content, floating lag time, total floating time and in vitro drug release). ${ }^{24}$

\section{RESULTS AND DISCUSSION}

\section{Drug-polymer compatibility study}

FTIR spectra demonstrated that there was no major difference in the peaks of the drug in the physical mixtures containing polymers such as HPMC K15M $\left(3421 \mathrm{~cm}^{-1}, 3043 \mathrm{~cm}^{-1}, 1693 \mathrm{~cm}^{-1}, 1681 \mathrm{~cm}^{-1}\right.$ and $\left.1643 \mathrm{~cm}^{-1}\right)$, HPMC K100M $\left(852 \mathrm{~cm}^{-1}, 690 \mathrm{~cm}^{-1}\right.$ and $\left.578 \mathrm{~cm}^{-1}\right)$ and xanthan gum $\left(2819.73 \mathrm{~cm}^{-1}, 1268 \mathrm{~cm}^{-1}\right.$ and $\left.1091 \mathrm{~cm}^{-1}\right)$, when compared with the spectra of pure drug $(3421.48$ $\mathrm{cm}^{-1}, 3043.46 \mathrm{~cm}^{-1}, 2819.73 \mathrm{~cm}^{-1}, 1693.38 \mathrm{~cm}^{-1}, 1681.81 \mathrm{~cm}^{-1}$, $1643.24 \mathrm{~cm}^{-1}, 1268.07 \mathrm{~cm}^{-1}, 1091.63 \mathrm{~cm}^{-1}, 852.48 \mathrm{~cm}^{-1}$, $690.47 \mathrm{~cm}^{-1}$ and $\left.578.60 \mathrm{~cm}^{-1}\right)$. No important interface between the drugs with the employed polymers were perceived and therefore it could be specified that there was no inaptness between the drug and different polymers (Figure 1).

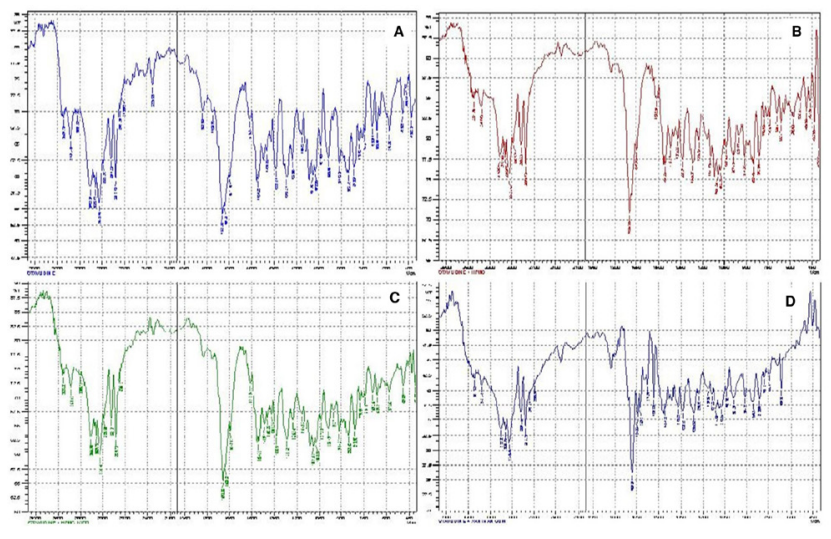

Figure 1: Drug-polymer compatibility analysis through FT-IR spectra: (A) Stavudine; (B) Stavudine + HPMC K15M; (C) Stavudine + HPMC K100M; and (D) Stavudine + Xanthan gum. 
DSC thermogram showed that there was no major difference in the onset temperature, end set temperature and peak temperature of the drug in the physical mixtures containing polymers such as HPMC K15M $\left(170.76^{\circ} \mathrm{C}\right)$, HPMC K100M $\left(159.59^{\circ} \mathrm{C}\right)$ and xanthan gum $\left(169.75^{\circ} \mathrm{C}\right)$, when compared with the spectra of thermogram pure drug $\left(172.24^{\circ} \mathrm{C}\right)$. No prominent interactions between drug and polymers were observed and therefore it could be specified that there was no such incongruity between the drug and different polymers (Figure 2).

\section{Characterization of pre-compression aspects}

The powder blends of formulations have the bulk density ranged between $0.732 \pm 0.01$ to $0.745 \pm 0.01 \mathrm{gm} / \mathrm{mL}$. The powder blends of formulations have the tapped bulk density ranged between $0.822 \pm 0.01$ to $0.838 \pm 0.00$ $\mathrm{gm} / \mathrm{mL}$ (Table 2). These values indicate good packing characteristics and the powder was not bulky. Carr's index for all the fabricated batches was recognized to be below $12 \%$ (range: $10.86 \%$ to $11.14 \%$ ) indicating that

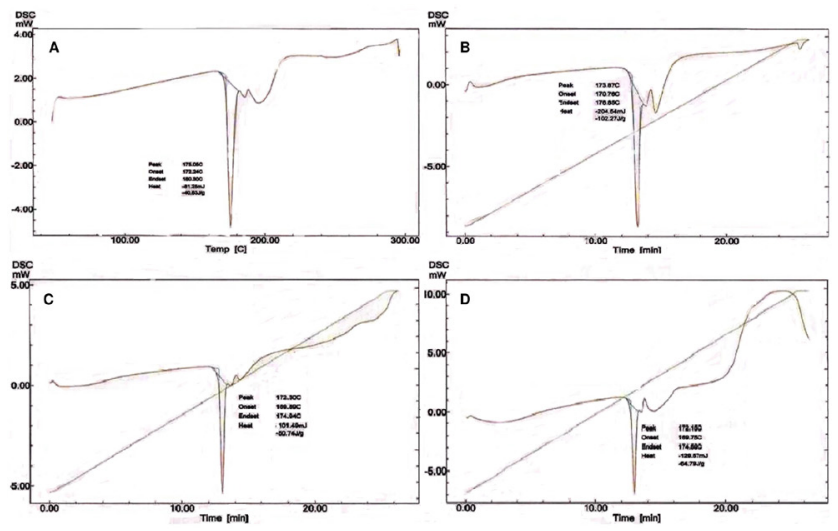

Figure 2: Drug-polymer compatibility analysis through DSC thermograms: (A) Stavudine; (B) Stavudine + HPMC K15M; (C) Stavudine + HPMC K100M; and (D) Stavudine + Xanthan gum. the powders have excellent compressibility. The Hausner's ratio for all the formulated batches was observed to be <1.25 (range: 1.121 to 1.125 ), indicating good flow properties. The flow properties of granules were analyzed by determining the angle of repose which was found to be between $20.29 \pm 0.21$ to $22.11 \pm 0.21$, indicating excellent flow property.

\section{Characterization of post-compression aspects}

The formulations were visually examined and none of the tablets presented common imperfection such as chipping, lamination and capping.

The physical attributes of stavudine floating tablets (F1 to F9) such as thickness, diameter, hardness, friability, weight variation and drug content were determined and the results of the developed formulations were perceived to be within the limits specified in official monographs and pharmacopeia guidelines. The diameter and thickness specifications may be set on an individual product basis. There were no noticeable disparity in the diameter and thickness of formulations within each batch indicated a consistent performance of the granules all over the compression process. The size (diameter) of the tablets of all formulations was found to be $9.0 \pm 0.0 \mathrm{~mm}$ and thickness ranged between $3.15 \pm 0.12$ to $3.31 \pm 0.11 \mathrm{~mm}$.

A disparity in the formulation hardness revealed the distinction in porosity and tablet density which in turn are thought to produce various drug release patterns by influencing the penetration rate of the dissolution fluid over the product surface and gel barrier formation. The tablet hardness was observed to lie within the range of $5.5 \pm 0.44 \mathrm{~kg} / \mathrm{cm}^{2}$ to $5.8 \pm 0.25 \mathrm{~kg} / \mathrm{cm}^{2}$. This indicates good tablet strength (Table 3 ).

The percentage friability of all the formulations was found between $0.28 \% \pm 0.06$ to $0.41 \% \pm 0.05$ which indi-

\begin{tabular}{|c|c|c|c|c|c|}
\hline $\begin{array}{l}\text { Formulation } \\
\text { Code }\end{array}$ & $\begin{array}{c}\text { Loose bulk } \\
\text { density } \\
\left(\mathrm{gm} / \mathrm{cm}^{3}\right)\end{array}$ & $\begin{array}{c}\text { Tapped bulk } \\
\text { density } \\
\left(\mathrm{gm} / \mathrm{cm}^{3}\right)\end{array}$ & $\begin{array}{c}\text { Hausner } \\
\text { ratio }\end{array}$ & Carr's index & $\begin{array}{l}\text { Angle of repose } \\
\qquad\left(\theta^{\circ}\right)\end{array}$ \\
\hline F1 & $0.745 \pm 0.01$ & $0.838 \pm 0.00$ & $1.124 \pm 0.001$ & $11.12 \pm 0.06$ & $21.17 \pm 0.21$ \\
\hline F2 & $0.732 \pm 0.01$ & $0.822 \pm 0.01$ & $1.122 \pm 0.00$ & $10.93 \pm 0.05$ & $21.19 \pm 0.58$ \\
\hline F3 & $0.743 \pm 0.00$ & $0.836 \pm 0.01$ & $1.125 \pm 0.00$ & $11.11 \pm 0.05$ & $20.54 \pm 0.49$ \\
\hline F4 & $0.743 \pm 0.02$ & $0.836 \pm 0.02$ & $1.124 \pm 0.001$ & $11.11 \pm 0.06$ & $22.11 \pm 0.21$ \\
\hline F5 & $0.732 \pm 0.00$ & $0.822 \pm 0.01$ & $1.121 \pm 0.005$ & $10.86 \pm 0.06$ & $20.82 \pm 0.11$ \\
\hline F6 & $0.733 \pm 0.01$ & $0.823 \pm 0.02$ & $1.122 \pm 0.001$ & $10.96 \pm 0.07$ & $20.29 \pm 0.21$ \\
\hline F7 & $0.745 \pm 0.01$ & $0.838 \pm 0.00$ & $1.124 \pm 0.005$ & $11.12 \pm 0.06$ & $21.39 \pm 0.47$ \\
\hline F8 & $0.732 \pm 0.01$ & $0.822 \pm 0.01$ & $1.121 \pm 0.001$ & $10.89 \pm 0.06$ & $20.59 \pm 0.50$ \\
\hline F9 & $0.744 \pm 0.02$ & $0.837 \pm 0.01$ & $1.125 \pm 0.005$ & $11.14 \pm 0.05$ & $20.76 \pm 0.78$ \\
\hline
\end{tabular}




\begin{tabular}{|c|c|c|c|c|c|c|}
\hline \multicolumn{7}{|c|}{ Table 3: Post-compression characteristics of stavudine floating tablet formulations. } \\
\hline $\begin{array}{c}\text { Formulation } \\
\text { Code }\end{array}$ & Diameter $(\mathbf{m m})$ & $\begin{array}{c}\text { Thickness } \\
\mathbf{( m m})\end{array}$ & $\begin{array}{c}\text { Hardness } \mathbf{( k g /} \\
\left.\mathbf{c m}^{\mathbf{2}}\right)\end{array}$ & Friability $\mathbf{( \% )}$ & $\begin{array}{c}\text { Weight variation } \\
\mathbf{( \% )}\end{array}$ & $\begin{array}{c}\text { Drug content } \mathbf{( \%} \\
\mathbf{w} / \mathbf{w})\end{array}$ \\
\hline F1 & $9.0 \pm 0.0$ & $3.18 \pm 0.14$ & $5.8 \pm 0.25$ & $0.41 \pm 0.05$ & \pm 2.11 & $99.81 \pm 1.4$ \\
\hline F2 & $9.0 \pm 0.0$ & $3.16 \pm 0.12$ & $5.7 \pm 0.27$ & $0.31 \pm 0.08$ & \pm 2.16 & $99.67 \pm 1.7$ \\
\hline F3 & $9.0 \pm 0.0$ & $3.15 \pm 0.12$ & $5.5 \pm 0.44$ & $0.36 \pm 0.03$ & \pm 2.02 & $98.75 \pm 0.5$ \\
\hline F4 & $9.0 \pm 0.0$ & $3.28 \pm 0.11$ & $5.6 \pm 0.41$ & $0.37 \pm 0.01$ & \pm 1.75 & $99.47 \pm 1.3$ \\
\hline F5 & $9.0 \pm 0.0$ & $3.13 \pm 0.10$ & $5.7 \pm 0.27$ & $0.36 \pm 0.08$ & \pm 2.46 & $100.07 \pm 0.5$ \\
\hline F6 & $9.0 \pm 0.0$ & $3.23 \pm 0.16$ & $5.58 \pm 0.62$ & $0.28 \pm 0.06$ & \pm 1.85 & $100.38 \pm 0.8$ \\
\hline F7 & $9.0 \pm 0.0$ & $3.18 \pm 0.14$ & $5.58 \pm 0.37$ & $0.41 \pm 0.03$ & \pm 1.89 & $100.01 \pm 1.7$ \\
\hline F8 & $9.0 \pm 0.0$ & $3.21 \pm 0.14$ & $5.5 \pm 0.44$ & $0.36 \pm 0.12$ & \pm 1.86 & $98.24 \pm 0.6$ \\
\hline F9 & $9.0 \pm 0.0$ & $3.31 \pm 0.11$ & $5.66 \pm 0.32$ & $0.34 \pm 0.10$ & \pm 1.90 & $99.39 \pm 1.5$ \\
\hline
\end{tabular}

\begin{tabular}{|c|c|c|}
\hline \multicolumn{3}{|c|}{ Table 4: In vitro buoyancy of stavudine floating } \\
tablet formulations.
\end{tabular}

cated good handling property of the prepared floating tablet that will handle transport oriented wear and tear. A tablet is formed to enclose a definite quantity of the drug. When the average mass of the tablet is $500 \mathrm{mg}$ the pharmacopoeia limit for percentage deviation is $\pm 5 \%$. The $\%$ average tablet weight deviations for all batches were observed to lie within the particular pharmacopoeia specifications and therefore all the batches complied with the specified weight variation guidelines.

The content of active ingredients in the formulation was found to be between $98.24 \pm 0.6$ to $100.38 \pm 0.8 \%$ w/w, which was with accordance to the particular Indian pharmacopeia limit.

All the formulations exhibited short floating lag times owing to the sodium bicarbonate contents. The formulation containing the low-viscosity grade HPMC K100 displayed short floating lag time and floated for a longer period as compared to the formulations having high viscosity grade xanthan gum and HPMC K15M. This designated that the viscosity of the polymer HPMC or molecular weight distribution that eventually influence the in-vitro buoyancy. All the prepared tablets show the

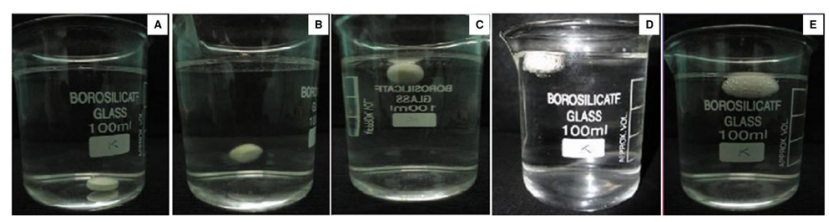

Figure 3: Floating characteristics of the stavudine tablet formulation: (A) At initial time; (B) Tablet started to rise up;

(C) After $93 \mathrm{sec}$; (D) After 6 hrs; and (E) After 12 hrs.

total floating time $>24$ hrs except the F1 batch shows only more than $12 \mathrm{hr}$ (Table 4). From the observations, it can be indicated that as the overall polymeric concentration augments, a decline in the floating lag time and an augmentation in the total floating time happens. The floating lag times of the formulations were observed to be the function of polymer concentration. This may be because due to low gelation attributes of polymers at a lower concentration. Hence, HPMC K100M polymer demonstrated good floating characteristics. The floating characteristics of the fabricated stavudine tablet formulation are depicted in Figure 3.

The swelling ratio expressed the quantity of water present within the formulation at equilibrium and was a component of hydrophilicity, network structure and the functional groups ionization. For $12 \mathrm{hr}$, the swelling study was carried out for formulations. The data acquired for the swelling index and the plot of swelling index against the time of different formulations with different concentrations of polymers are depicted. From the obtained data, it was seen that with the passage of time, the swelling augments as the polymer absorbs high amount of water gradually owing to hydrophilicity characteristics. The outermost hydrophilic polymer hydrates and swells and a gel barrier are formed at the outer surface. Xanthan gum and HPMC are hydrophilic polymers and depending on the substitution and molecular weight, they dissolve more or less rapidly. When this matrix comes in contact with 


\begin{tabular}{|c|c|c|c|c|c|c|c|c|c|}
\hline \multirow{2}{*}{$\begin{array}{c}\text { Time } \\
\text { (hours) }\end{array}$} & \multicolumn{9}{|c|}{ Swelling Index } \\
\hline & F1 & F2 & F3 & F4 & F5 & F6 & F7 & F8 & F9 \\
\hline 1 & $0.76 \pm 0.015$ & $0.97 \pm 0.02$ & $1.21 \pm 0.015$ & $1.25 \pm 0.025$ & $1.59 \pm 0.05$ & $1.74 \pm 0.020$ & $1.01 \pm 0.017$ & $1.22 \pm 0.020$ & $1.52 \pm 0.015$ \\
\hline 2 & $0.92 \pm 0.015$ & $1.21 \pm 0.015$ & $1.49 \pm 0.020$ & $1.53 \pm 0.045$ & $1.91 \pm 0.025$ & $1.91 \pm 0.020$ & $1.46 \pm 0.020$ & $1.57 \pm 0.015$ & $1.88 \pm 0.015$ \\
\hline 3 & $1.02 \pm 0.030$ & $1.34 \pm 0.015$ & $1.76 \pm 0.020$ & $1.69 \pm 0.030$ & $2.19 \pm 0.015$ & $2.04 \pm 0.015$ & $1.66 \pm 0.005$ & $1.82 \pm 0.015$ & $2.19 \pm 0.015$ \\
\hline 4 & $1.26 \pm 0.015$ & $1.63 \pm 0.026$ & $1.89 \pm 0.015$ & $1.91 \pm 0.025$ & $2.4 \pm 0.020$ & $2.21 \pm 0.010$ & $1.8 \pm 0.015$ & $2.02 \pm 0.015$ & $2.58 \pm 0.020$ \\
\hline 5 & $1.42 \pm 0.015$ & $1.7 \pm 0.030$ & $2.02 \pm 0.015$ & $2.13 \pm 0.025$ & $2.53 \pm 0.015$ & $2.59 \pm 0.015$ & $1.97 \pm 0.010$ & $2.2 \pm 0.015$ & $2.58 \pm 0.015$ \\
\hline 6 & $1.66 \pm 0.015$ & $1.95 \pm 0.015$ & $2.17 \pm 0.015$ & $2.37 \pm 0.020$ & $2.78 \pm 0.015$ & $2.91 \pm 0.015$ & $2.19 \pm 0.015$ & $2.47 \pm 0.020$ & $2.99 \pm 0.015$ \\
\hline 7 & $2.04 \pm 0.02$ & $2.18 \pm 0.015$ & $2.45 \pm 0.015$ & $2.63 \pm 0.020$ & $2.92 \pm 0.015$ & $3.02 \pm 0.015$ & $2.33 \pm 0.015$ & $2.8 \pm 0.020$ & $3.15 \pm 0.032$ \\
\hline 8 & $2.1 \pm 0.015$ & $2.4 \pm 0.025$ & $2.56 \pm 0.015$ & $2.91 \pm 0.020$ & $2.99 \pm 0.01$ & $3.1 \pm 0.015$ & $2.61 \pm 0.020$ & $2.97 \pm 0.015$ & $3.31 \pm 0.015$ \\
\hline 9 & $1.95 \pm 0.015$ & $2.74 \pm 0.020$ & $2.93 \pm 0.020$ & $2.64 \pm 0.025$ & $3.21 \pm 0.015$ & $3.35 \pm 0.025$ & $2.8 \pm 0.015$ & $3.16 \pm 0.020$ & $3.42 \pm 0.015$ \\
\hline 10 & $1.83 \pm 0.02$ & $2.58 \pm 0.005$ & $2.82 \pm 0.020$ & $2.45 \pm 0.025$ & $3.03 \pm 0.015$ & $3.23 \pm 0.015$ & $2.68 \pm 0.015$ & $3.32 \pm 0.015$ & $3.57 \pm 0.020$ \\
\hline 11 & $1.62 \pm 0.015$ & $2.27 \pm 0.015$ & $2.69 \pm 0.015$ & $2.27 \pm 0.025$ & $2.87 \pm 0.025$ & $2.97 \pm 0.015$ & $2.48 \pm 0.015$ & $3.2 \pm 00.015$ & $3.35 \pm 0.032$ \\
\hline 12 & $1.54 \pm 0.02$ & $2.03 \pm 0.015$ & $2.46 \pm 0.015$ & $2.08 \pm 0.030$ & $2.71 \pm 0.02$ & $2.81 \pm 0.015$ & $2.33 \pm 0.020$ & $3.04 \pm 0.020$ & $3.19 \pm 0.015$ \\
\hline
\end{tabular}

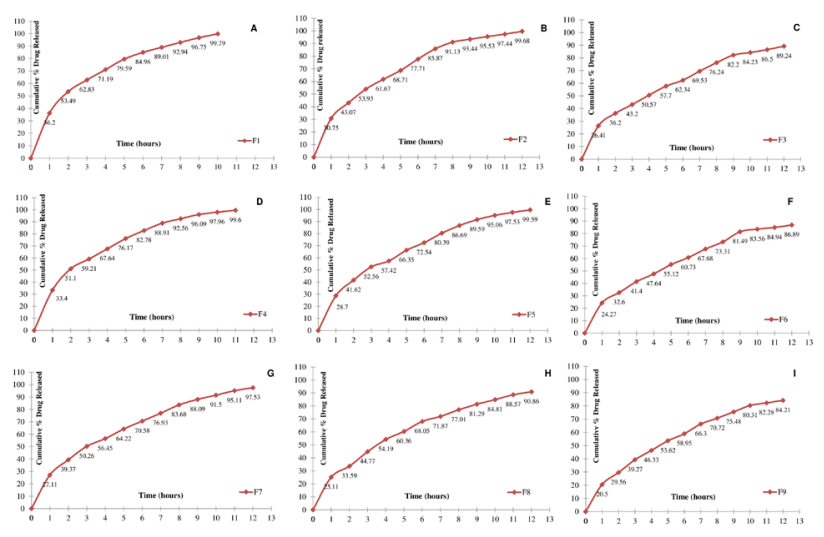

Figure 4: In vitro drug release profile of stavudine floating tablet formulations (F1 to F9).

water or aqueous gastrointestinal fluid, the polymer absorbs the water and undergoes swelling and hydrates. Tablet hydration capacity was important to be considered because the water penetration was responsible for drug release. From the study, it was observed that xanthan gum and HPMC K100M showed good swelling as compared to HPMC $\mathrm{K} 15 \mathrm{M}$, which indicates that the rate of swelling was directly proportional to the viscosity of polymer, since xanthan gum and HPMC K100M have more viscosity than HPMC K15M. The formulations (F3, F6 and F9) containing the highest concentration (40\%) of each polymer showed the highest swelling index (Table 5). The maximum swelling indices were attained in 7-9 hrs, 8-9 hr and 9-10 hrs for HPMC K15M, xanthan gum and HPMC K100M, respectively, after which the polymer started eroding slowly in the medium.
Stavudine was a water-soluble drug; its release from the matrix was largely dependent on the polymer swelling, drug diffusion and matrix erosion. The polymeric concentration in the product was a key factor in supporting the release of drug. The drug release from formulations F1-F3 containing HPMC K15M at three concentration levels of $13.5 \%, 27 \%$ and $40 \%$ was found to be $99.79 \pm 0.25 \%, 99.68 \pm 0.26 \%$ and $89.24 \pm 0.85 \%$, respectively. The drug release from formulation F4-F6 containing HPMC K100M at three concentration levels of $13.5 \%, 27 \%$ and $40 \%$ was found to be $99.60 \pm 0.26 \%$, $99.59 \pm 0.39 \%$ and $86.89 \pm 0.37 \%$, respectively. While the drug release from formulation F7-F9 containing xanthan gum at three concentration levels of $13.5 \%, 27 \%$ and $40 \%$ was found to be $97.53 \pm 0.41 \%$, $90.86 \pm 0.43 \%$ and $84.21 \pm 0.57 \%$, respectively (Figure 4). When cumulative $\%$ drug release plotted versus time, it was noticed that, for three of the polymers used, an increase in the polymeric concentration from $13.5 \%$ to $40 \%$, induce a lessening in the drug release rate. The drug release rate from the xanthan gum matrix was observed to be less as compared to HPMC K15M and HPMC K100M. This might be owing to the sluggish hydration of the formulation matrix and its attributes to create a thick layer of gel, which retard the drug release from the tablet. Whereas formulation containing HPMC K15M (F1-F3) gave higher drug release as compared to the formulation containing HPMC K100M (F4-F6) and xanthan gum (F7-F9), which may be due to quick hydration of polymer matrix, after which matrix might get started to erode. In addition to the concentration of polymer, the type and viscosity of polymer also influence drug release. When the drug 


\begin{tabular}{|c|c|c|c|c|c|c|c|c|c|}
\hline \multirow[t]{2}{*}{ Batch } & \multicolumn{2}{|c|}{ Zero order } & \multicolumn{2}{|c|}{ First order } & \multicolumn{2}{|c|}{ Higuchi } & \multicolumn{2}{|c|}{ Korsmeyer-Peppas } & \multirow{2}{*}{$\begin{array}{l}\text { Best fit } \\
\text { model }\end{array}$} \\
\hline & $R^{2}$ & $\mathrm{~K}_{0}\left(\mathrm{mg} / \mathrm{h}^{-1}\right)$ & $R^{2}$ & $\mathrm{~K}_{1}\left(\mathrm{~h}^{-1}\right)$ & $R^{2}$ & $\begin{array}{c}\mathrm{K} \\
\left(\mathrm{mg} \mathrm{h}^{-1}\right)\end{array}$ & $R^{2}$ & $\mathbf{n}$ & \\
\hline $\mathrm{F} 1$ & 0.7653 & 0.2060 & 0.8648 & 0.0072 & 0.9903 & 4.3504 & 0.9947 & 0.4335 & Peppas \\
\hline $\mathrm{F} 2$ & 0.8305 & 0.1722 & 0.9086 & 0.0059 & 0.9945 & 3.9429 & 0.9949 & 0.5040 & Peppas \\
\hline F3 & 0.8805 & 0.1486 & 0.9947 & 0.0030 & 0.9977 & 3.3831 & 0.9970 & 0.5119 & Higuchi \\
\hline F4 & 0.7761 & 0.1899 & 0.9406 & 0.0064 & 0.9916 & 4.1901 & 0.9938 & 0.4542 & Peppas \\
\hline F5 & 0.8618 & 0.1684 & 0.8979 & 0.0055 & 0.9983 & 3.8121 & 0.9981 & 0.5113 & Higuchi \\
\hline F6 & 0.9031 & 0.1449 & 0.9936 & 0.0029 & 0.9952 & 3.2893 & 0.9963 & 0.5459 & Peppas \\
\hline F7 & 0.8706 & 0.1631 & 0.9693 & 0.0043 & 0.9988 & 3.7182 & 0.9988 & 0.5225 & Higuchi \\
\hline F8 & 0.8766 & 0.1517 & 0.9970 & 0.0032 & 0.9979 & 3.4572 & 0.9968 & 0.5389 & Higuchi \\
\hline F9 & 0.9149 & 0.1393 & 0.9978 & 0.0026 & 0.9949 & 3.1577 & 0.9983 & 0.5900 & Peppas \\
\hline
\end{tabular}

release data acquired from the dissolution analysis of diverse polymers at $13.5 \%$ concentration is plotted against the time, it was detected that low concentration of polymer induces more drug release. This is owing to the creation of a thin barrier around the formulation through which drug can diffuse from polymer matrices. Among three polymers, HPMC K15M at three concentration levels $(13.5 \%, 27 \%$ and $40 \%)$ gave more drug release as compared to xanthan gum and HPMC $\mathrm{K} 100 \mathrm{M}$, as it has low viscosity as compared to xanthan gum and HPMC K100M. A huge quantity of highly viscous polymeric contents tempted the development of gelatinous layer that deliberately diminished the water diffusion rate into the tablet matrix and therefore resulted in the reducing the release of drug.

The comparative effect of three diverse polymeric contents over the release profile of stavudine from the floating formulations in terms of percentage dissolution efficiency (\% DE) showed that formulations containing xanthan gum delayed the drug release than those containing HPMC K15M and HPMC K100M. It was observed that formulations having low values of mean dissolution time (MDT) indicated the faster release of the drug than the other formulations.

The release profiles of all the formulation batches were made to fit in different models. But the superiority of other models was however statistically insignificant with the Higuchi matrix model as depicted by the goodness of fit test (t-test). Thus, it may be concluded that the drug release from the regiospecific floating tablet of stavudine is best explained by Higuchi's matrix model (Table 6).

The intercept and values of slope for the Higuchi's matrix model were used to find out time required to release $25 \%$ drug $\left(\mathrm{t}_{25}\right)$, time taken to release $50 \%$ drug
Table 7: Time of drug release values of $t_{25}, t_{50}$ and $t_{90}$ for stavudine floating tablet formulations.

\begin{tabular}{|c|c|c|c|}
\hline \multirow{2}{*}{ Formulation code } & \multicolumn{3}{|c|}{ Time of $\%$ drug release $\mathbf{( h r s )}$} \\
\cline { 2 - 4 } & $\mathbf{2 5 \%} \mathbf{( t}_{\mathbf{2 5}} \mathbf{)}$ & $\left.\mathbf{5 0} \% \mathbf{( t}_{\mathbf{5 0}}\right)$ & $\mathbf{9 0} \% \mathbf{( t}_{\mathbf{9 0}} \mathbf{)}$ \\
\hline F1 & 0.42 & 1.93 & 7.24 \\
\hline F2 & 0.65 & 2.62 & 8.73 \\
\hline F3 & 0.92 & 3.65 & $>12$ \\
\hline F4 & 0.51 & 2.10 & 7.72 \\
\hline F5 & 0.83 & 2.77 & 9.16 \\
\hline F6 & 1.25 & 4.21 & $>12$ \\
\hline F7 & 0.83 & 2.98 & 9.51 \\
\hline F8 & 0.91 & 3.54 & $>12$ \\
\hline F9 & 1.42 & 4.65 & $>12$ \\
\hline
\end{tabular}

$\left(\mathrm{t}_{50}\right)$ and time taken to release $90 \%$ drug $\left(\mathrm{t}_{-90}\right)$ drug for each batch (F2, F5 and F7) of the best formulation of HPMC K15M, xanthan gum and HPMC K100M polymers (Table 7). The drug release profile of selected formulations shows that the formulation F5 showed the sustained drug release profile for $12 \mathrm{hrs}$ as compared to formulations F2 and F7. It is observed from in vitro buoyancy study and swelling index that formulation F5 shown less floating lag time $(93 \mathrm{sec})$ with good total floating time (>24 hrs) and higher swelling index as compared to selected formulations F2 and F7. From the above study, it was indicated that the product F5 showed the sustained drug release profile with good matrix integrity, less floating lag time with higher swelling index and good total floating time as compared with the selected batches for this reason the formulation F5 was deemed as the most optimized product among other formulations of this series. Hence, the formulation F5 was selected for the further stability study. 


\begin{tabular}{|c|c|c|c|c|}
\hline \multicolumn{5}{|c|}{ Table 8: Stability studies of optimized formulation (F5). } \\
\hline Characteristics & Initials & 1 Month & 2 Month & 3 Month \\
\hline Hardness $\left(\mathbf{k g} / \mathbf{c m}^{2}\right)$ & $5.7 \pm 0.27$ & $5.83 \pm 0.288$ & $5.66 \pm 0.288$ & $5.83 \pm 0.288$ \\
\hline Drug content $(\mathbf{m g} /$ tablet) & $100.07 \pm 0.5$ & $100.04 \pm 1.5$ & $99.39 \pm 1.5$ & $99.47 \pm 1.32$ \\
\hline Floating lag time (sec) & $93 \pm 1.52$ & $98 \pm 2.64$ & $95 \pm 2.00$ & $97 \pm 2.64$ \\
\hline Total floating time (hr) & $>24$ & $>24$ & $>24$ & $>24$ \\
\hline In vitro drug release at $12^{\text {th }} \mathbf{~ h r}$ & $99.59 \pm 0.39$ & $99.21 \pm 0.15$ & $98.16 \pm 0.36$ & $98.07 \pm 0.11$ \\
\hline
\end{tabular}

No major difference was found between evaluated parameters before and after stability studies and all was found to be within acceptable limits (Table 8). The tablets showed agreeable physical stability at $40^{\circ} \mathrm{C}$ temperature and $75 \% \mathrm{RH}$.

\section{CONCLUSION}

The current research endeavors towards the development of stavudine floating tablet formulations (F1-F9) employing rate modifying polymers such as HPMC K15M, xanthan gum and HPMC K100M using multiple punch tablet compression machine containing $9 \mathrm{~mm}$ diameter, round flat-faced punches to form $80 \mathrm{mg}$ tablet with a batch size of 100 . The pre-compression characteristics demonstrated that the powders have excellent compressibility, excellent flow property, good packing characteristics and the powder was not bulky. The formulations showed no defects such as chipping, capping and lamination. The post-compression attributes of the tablets such as drug content, friability, hardness and weight variation were found to be within the limits specified in Indian Pharmacopoeia. A desired level of the in vitro dissolution levels, swelling index and in vitro buoyancy levels were observed for all the formulations. No major differences was found between evaluated parameters before and after stability studies and all were found to be within acceptable limits. No important interface between the drugs with the employed polymers was perceived in any formulations. This research study on stavudine will definitely open several new milestones for anti-retroviral pharmacotherapeutics in the upcoming future perspectives by enhancing the half-life of the drug employing the floating extended-release attributes.

\section{ACKNOWLEDGEMENT}

The authors are thankful to the Dadasaheb Balpande College of Pharmacy management for providing research facilities and support for performing this study.

\section{CONFLICT OF INTEREST}

The authors declare no Conflict of interest.

\section{ABBREVIATIONS}

FTIR: Fourier Transformed Infrared Spectroscopy; XRD: X-ray Diffraction; DSC: Differential Scanning Calorimetry; ICH: International Council for Harmonization of Technical Requirements for Pharmaceuticals for Human Use.

\section{REFERENCES}

1. Borkar SS, Mahapatra DK, Wakodkar SB, Baheti JR. Pharmacology-III. Nagpur: ABD Publications Private Limited; 2020.

2. Puranik MP, Mahapatra DK. Medicinal chemistry-III. Nagpur: ABD Publications Private Limited; 2020.

3. Mahapatra DK, Bharti SK. Handbook of research on medicinal chemistry: innovations and methodologies. NJ: Apple Academic Press; 2017.

4. Mahapatra DK, Bharti SK. Medicinal chemistry with Pharmaceutical Product Development. NJ: Apple Academic Press; 2019.

5. Mahapatra DK, Bharti SK. Drug design. New Delhi: Tara Verlag Publications Private Limited; 2016.

6. Chhajed M, Shrivastava AK, Chhajed A, Taile V, Prachand S, Jain S. Computational evaluation of 2-amino-5-sulphonamido-1,3,4-thiadiazoles as human carbonic anhydrase-IX inhibitors: an insight into the structural requirement for the anticancer activity against HEK 293. Med Chem Res. 2017;26(10):2272-92. doi: 10.1007/s00044-017-1929-3.

7. Mahapatra DK, Shivhare RS. Medicinal chemistry-II. Nagpur: ABD Publications Private Limited; 2019.

8. Chhajed SS, Bastikar V, Bastikar AV, Mahapatra DK. Computer aided drug design. Pune: Everest Publishing House; 2019.

9. Mahor S, Kant Prasad N, Chandra P. A Review on Recent Trends in the Development of Gastro Retentive Floating Drug Delivery System. Indo Glob J Pharm Sci. 2019;09(1):13-24. doi: 10.35652/IGJPS.2019.9103.

10. Maniyar MM, Patil PB, Saudagar RB. Effervescent floating drug delivery system: a review. J Drug Deliv Ther. 2019;9(4-A):771-2.

11. Jaimini R, Gupta MK, Sharma V. A review on formulation and evaluation of gastroretentive floating tablet of nifedipine. J Drug Deliv Ther. 2019;9(4):651-6.

12. Dhawale P, Mahajan NM, Mahapatra DK, Mahajan UN, Gangane PS. HPMC K15M and Carbopol 940 mediated fabrication of ondansetron hydrochloride intranasal mucoadhesive microspheres. J Appl Pharm Sci. 2018;8(8):75-83. 
13. Dangre PV, Godbole MD, Ingle PV, Mahapatra DK. Improved dissolution and bioavailability of EprosartanMesylate formulated as solid dispersions using conventional methods. Indian J Pharm Educ Res. 2016;50(3):S209-17.

14. Mahajan NN, Wadhavane P, Mahapatra DK. Rational designing of sustained release matrix formulation of etodolac employing hypromellose, carbomer, Eudragit and povidone. Int J Pharm Pharm Sci. 2017;9(12):92-7. doi: 10.22159/ijpps.2017v9i12.19702.

15. Mahajan NM, Pardeshi A, Mahapatra DK, Darode A, Dumore NG. Hypromellose and carbomer induce bioadhesion of acyclovir tablet to vaginal mucosa. Indo Am J Pharm Res. 2017;7(12):1108-18.

16. Patil MD, Mahapatra DK, Dangre PV. Formulation and in-vitro evaluation of once-daily sustained release matrix tablet of nifedipine using rate retardant polymers. Inventi Impact Pharm Tech. 2016;4:190-6.

17. Gangane PS, Kadam MM, Mahapatra DK, Mahajan NM, Mahajan UN. Design and formulating gliclazide solid dispersion immediate release layer and metformin sustained release layer in bilayer tablet for the effective postprandial management of diabetes mellitus. Int $\mathrm{J}$ Pharm Sci Res. 2018;9(9):3743-56.

18. Kazi FS, Mahajan RK, Mahapatra DK, Mahajan UN. Formulation development of innovator equivalent extended release tablets of gliclazide: A way ahead to Generic medicines. J PharmSci Pharmacol. 2017;3:1-8.
19. Pusala SV, Gangane PS, Mahapatra DK, Mahajan NM. Hydrophilic and hydrophobic matrix system engineered development of extended release tablets of oxybutynin chloride. Int J Pharm Sci Res. 2020;11(9):4603-11.

20. Mahendar R, Ramakrisha K. Formulation and evaluation of floating matrix tablets of stavudine using pullulan gum. Int J Chem PharmSci. 2012;3(2):80-3.

21. Gangane PS, Ghughuskar SH, Mahapatra DK, Mahajan NM. Evaluating the role of Celosia argentea powder and fenugreek seed mucilage as natural super-disintegrating agents in gliclazide fast disintegrating tablets. Int J Curr Res Rev. 2020;12(17):101-8. doi: 10.31782/IJCRR.2020.12173.

22. Godbole MD, Mahapatra DK, Khode PD. Fabrication and characterization of edible jelly formulation of stevioside: A nutraceutical or OTC aid for the diabetic patients. Inventi Rapid Nutraceut. 2017;2:1-9.

23. Khan S, Gangane PS, Mahapatra DK, Mahajan NM. Natural and synthetic Polymers assisted Development of lurasidone hydrochloride intranasal mucoadhesive Microspheres. Indian J Pharm Educ Res. 2019;54(1):213-22. doi: 10.5530/ijper.54.1.25.

24. Sonkusre N, Dhabarde DM, Mahapatra DK. Formulation and development of mirtazapine self emulsifying drug delivery system (SEDDS) for enhancement of dissolution profile. Inventi Impact NDDS. 2016;4:155-63.

\section{PICTORIAL ABSTRACT}

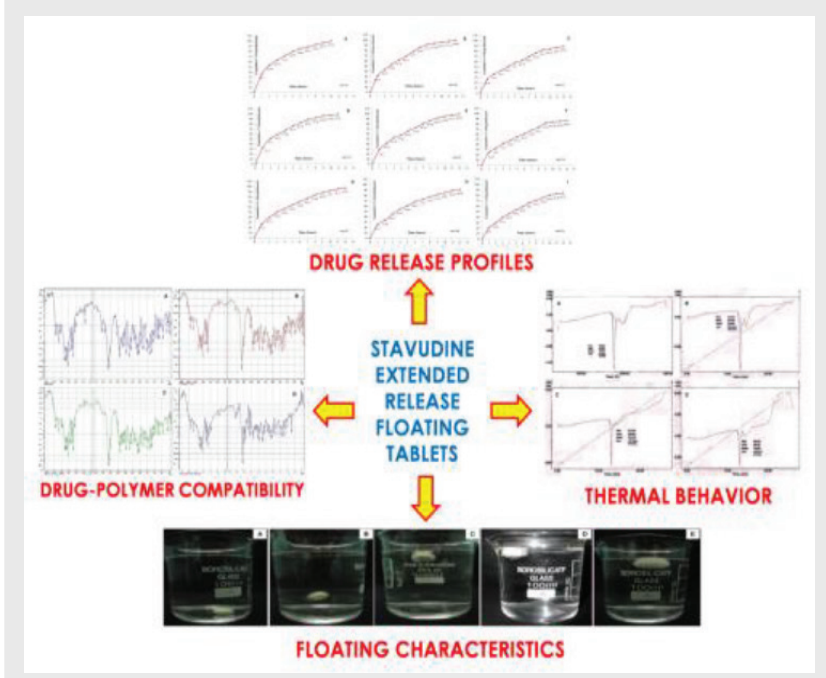

\section{SUMMARY}

- Stavudine has a low half-life and therefore needs recurrent administration to sustain stable beneficial drug plasma levels which was successfully achieved through gastroretentive systems.

- The research endeavors towards the development of stavudine floating tablet formulations employing rate modifying polymers such as HPMC K15M, HPMC K100M and xanthan gum.

- The formulations were successfully developed and the pre-compression characteristics (bulk density, tapped density, Carr's index, Hausner's ratio and angle of repose) were studied.

- The post-compression characteristics (appearance, dimension, hardness, friability, drug content, weight variation, swelling index, in vitro buoyancy, in vitro drug release, drug release kinetics and accelerated stability for 90 days) of the formulations were studied.

\footnotetext{
About Authors

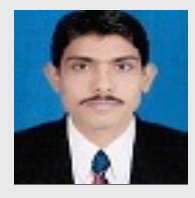

Purushottam Shridhar Gangane is working as an Associate Professor, Department of Pharmaceutics at Dadasaheb Balpande College of Pharmacy, Nagpur. He has more than 14 years of teaching and research experience. He has guided 18 post-graduate students under his supervision. He has published $15+$ research publications in the journals of repute and also authored several book chapters for international press. He has presented several papers in national as well as international conferences and received numerous awards. He is a life member of APTI and also a member of CRS-India Chapter. His areas of research expertise include nasal drug delivery and multiparticulate drug delivery system.

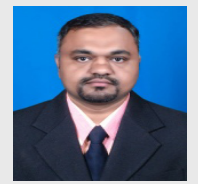

Tejas Pachpute has obtained his B. Pharm. degree from SGMPM's Sharadchandra Pawar College of Pharmacy (2010); M. Pharm. degree from I.B.S.S. College of Pharmacy (2012); and Ph.D. degree from SunRise University (2020). He has nearly 10 years of teaching, administrative, and academic research experience. He is current working as Principal (I/C) at BDSP's Siddhi's Institute of Pharmacy, Dist. Thane, Maharashtra.
} 
Debarshi Kar Mahapatra is currently an Assistant Professor at Department of Pharmaceutical Chemistry, Dadasaheb Balpande College of Pharmacy, Nagpur. He taught medicinal and computational chemistry at undergraduate and post-graduate levels and has mentored numerous students in various research projects. He has published several research papers, review articles, imperative case-studies in various reputed national and international journals and authored many book chapters. He presented his original contributions at several international platforms, for which he received several awards by a number of scientific and professional bodies. He has contributed several edited books, textbooks, lab manuals, book chapters, and guide books on Medicinal Chemistry, Computational Chemistry, and Pharmaceutics. Presently, he is serving as reviewer and editorial board member for several journals of national and international repute.

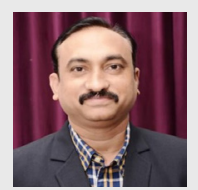

Nilesh Manoharrao Mahajan is working as a Professor and Head, Department of Pharmaceutics at Dadasaheb Balpande College of Pharmacy, Nagpur. He has $17+$ years of teaching and research experience. He has guided 50 + post-graduate students and 02 candidates are currently registered for $\mathrm{PhD}$. He has received one international patent published on 'Herbal based mosquito repellent'; owns one design copyright for 'Robotic jaw for the in-vitro dissolution testing of chewing gum'; and also published $50+$ research publications in the journals of repute. He is a recipient of RPS by AICTE in the year 2013. He has presented many papers and received several awards in conferences. $\mathrm{He}$ is an editorial board member of two scientific journals. He is a life member of APTI and also a member of CRS-India Chapter. His areas of research expertise are nanotherapeutics, crystal engineering, and polyherbal formulations.

Cite this article: Gangane PS, Pachpute T, Mahapatra DK, Mahajan NM. HPMC Polymers and Xanthan Gum Assisted Development and Characterization of Stavudine Extended Release Floating Tablets. Indian $\mathrm{J}$ of Pharmaceutical Education and Research. 2021;55(3s):s681-s692. 